\title{
FORMULASI SEDIAAN SABUN PADAT DARI MINYAK ATSIRI SEREH WANGI (Cymbopogon nardus $\mathrm{L}$ )
}

\author{
Betna Dewi ${ }^{1}$, Dewi Winni Fauzia ${ }^{2}$, Belinda Rahmadani Putri ${ }^{3}$ \\ ${ }^{1,2,3}$ Sekolah Tinggi KesehatanAl-Fatah Bengkulu \\ ${ }^{1}$ malaikakhadija1@gmail.com,
}

\begin{abstract}
ABSTRAK
Sabun merupakan salah satu sediaan kosmetik yang digunakan untuk perawatan dan pembersih kulit, Penggunaan serai wangi sebagai obat dan pewangi dapat meningkatkan estetika sabun.Penelitian ini merupakan penelitian mengenai minyak atsiri Sereh Wangi ( Cymbopogon nardur L )yang dibuat menjadi sediaan sabun padat.

Zat aktif yang digunakan adalah minyak atsiri sereh wangi, dengan konsentarsi $0 \%$ ( formula F0), konsentrasi 1\% ( formula F1 ), konsentari 3\% ( formula F2), dan konsentrasi 5\% ( formula F3 ). Prosedur kerja pembuatan sabun padat dengan metode dingin. Evaluasi sediaan meliputi uji organoleptis, uji $\mathrm{pH}$, uji tinggi busa, uji stabilitas busa

Minyak atsiri Sereh Wangi ( Cymbopogon nardur L )dapat dibuat menjadi formulasi sabun padat. Variasi konsentrasi minyak atsiri Sereh Wangi (Cymbopogon nardur $L$ ) formula F0,F1,F2 dan F3 dapat mempengaruhi sifat fisik sabun padat
\end{abstract}

Kata Kunci : Minyak Atsiri Sereh Wangi ( Cymbopogon nardur L )(Cymbopogon nardus L.)Formulasi Sabun Padat.

\section{METODE PENELITIAN}

\section{a. Alat}

Timbangan analitik, gelas ukur, beaker glass, cetakan sabun, sendok spatel, batang pengaduk, dan kotak kemasan sabun.

\section{b. Bahan}

Minyak atsiri sereh murni (Cymbopogon nardus L) Minyak kelapa, Minyak zaitun,Minyak sawit, $\mathrm{NaOH}$, Cocomid DEA, dan Aquadest.

\section{c. Pengumpulan Bahan Baku}

Sampel yang digunakan dalam penelitian ini berupa minyak atsiri sereh murni yang bersertifikat

\section{PEMBUATAN SABUN PADAT MINYAK ATSIRI SEREHWANGI (cymbopogon nardus $\mathrm{L}$ )}

\section{a. Rancangan Formula}

Penyusunan formula dengan menggunakan formula standar sabun dengan berbagai varian konsentrasiminyak atsiriSereh Wangi (Cymbopogon nardus L) sebagai zat aktifnya.Sediaan sabun padat ini dibuat dalam empat formula yaitu 
formula F0, formulaF1, formulaF2 dan formulaF3 dengan variasi minyak atsiri Sereh Wangi(Cymbopogon nardus L). Rancangan formula secara lengkap dapat dilihat pada table I.

\section{Tabel I.RancanganFormula SabunPadatMinyak Atsiri Sereh Wangi(Cymbopogon nardus $\mathbf{L}$ )}

(Sukawaty, 2016)

\section{Keterangan:}

F0 = Formula sabun padattanpa minyak sereh wangi

F2 = Formula sabun padat minyak Sereh Wangi (Cymbopogon nardur L) $1 \%$

F3 = Formula sabun padatminyak Sereh Wangi (Cymbopogon nardur L )3\%

$\mathrm{F} 4=$ Formula sabun padatminyak Sereh Wangi (Cymbopogon nardurL ) $5 \%$

\begin{tabular}{|l|c|c|c|c|}
\hline \multirow{2}{*}{ Bahan } & \multicolumn{4}{c|}{ Formula } \\
\cline { 2 - 6 } & F0 & F1 & F2 & F3 \\
\hline $\begin{array}{l}\text { Minyak Sereh } \\
\text { Wangi }\end{array}$ & - & 1 & 3 & 5 \\
\hline Minyak Sawit & 30 & 30 & 30 & 30 \\
\hline $\begin{array}{l}\text { Minyak Kelapa } \\
\text { Murni }\end{array}$ & 20 & 20 & 20 & 20 \\
\hline Minyak Zaitun & 10 & 10 & 10 & 10 \\
\hline NaOH & 8,9 & 8,9 & 8,9 & 8,9 \\
\hline Cocomid DEA & 0,1 & 0,1 & 0,1 & 0,1 \\
\hline Aqua dest ad & 100 & 100 & 100 & 100 \\
\hline
\end{tabular}

\section{b. Prosedur KerjaPembuatan}

\section{Sabun padat}

Timbang semua bahan sesuai dengan formula yang direncanakan. Masukkan $\mathrm{NaOH}$ kedalam aqua dest aduk sampai larut secara hati-hati, lalu dinginkan sampai suhu $45^{\circ} \mathrm{C}$. Masukan larutan alkali perlahanlahan kedalam campuran minyak, lalu aduk menggunakan batang pengaduk sampai homogen.Tambahkan minyak atsiri Sereh Wangi (Cymbopogon nardur L) danpewarna ke dalam adonan lalu aduk sampai homogen.

EVALUASI SABUN PADAT MINYAK ATSIRI SEREH WANGI L (CYMBOPOGON NARDUS L)

\section{a. Uji Organoleptis}

Uji organoleptis ini meliputi uji bentuk, warna, dan aroma dari sabun selama penyimpanan 2 minggu.

\section{b. Uji pH}

1 gram sabun dilarutkan dalam air sampai larut.pH diukur pada masing-masing formula sabun minyak atsiri sereh (Cymbopogon nardus L)dengan menggunakan alat $\mathrm{pH}$ meter Pengamatan dilakukan selama 2 minggu untuk mengetahui perubahan nilai $\mathrm{pH}$ sabun padat.

\section{c. Uji Tinggi Busa}

Cara kerjanya yaitu ambil sabun sebanyak 1 gram kemudian masukkan dalam tabung reaksi yang berisi $10 \mathrm{ml}$ aqua dest, lalu kocok selama 1 menit, kemudian busa sabun akan 
terbentuk.Busa yang terbentuk diukur tingginya menggunakanpenggaris

\section{d. Uji stabilitas busa}

Sabun sebanyak 1 gram dimasukan dalam gelas ukur yang berisi $10 \mathrm{ml}$ aquadest, kemudian dikocok selama 30 detik.Busa yang terbentuk diukur tingginya menggunakan penggaris (tinggi busa awal). Tinggi busa diukur kembali setelah 1 jam (tinggi busa akhir), .(Fatimah dan Jamilah, 2018) kemudian stabilitas busa dihitung dengan rumus:

$$
\% \text { Busa yang Hilang } \frac{\text { Tinggi busa awal - Tinggi busa akhir }}{\text { Tinggi busa awal }} \times 100 \%
$$

\section{e. Analisis Data}

Data yang diperoleh dari hasil penelitian selanjutnya akan diolah dan dianalisis dalam bentuk tabel dan grafik.

\section{HASIL DAN PEMBAHASAN}

\section{Uji Sifat Fisik Sabun Padat Minyak}

\section{Sereh Wangi(Cymbopogon nardus}

L.)

Uji sifat Fisiksabun bertujuan untuk mengetahui perubahan Fisik yang terjadi pada penyimpanan pada suhu kamar, Uji sifat Fisiksabun terdiri dari Uji organoleptis, uji $\mathrm{pH}$, Uji tinggi busa, Uji Stabilitas Busa, Uji Hedonik

\section{a. Uji Organoleptis Sabun Padat}

Pengujiandilakukan

setelahprosespembuatansabunyangbert ujuan untuk mengamati perbedaan bentuk Fisik sabun dari keempat formulasi hasil uji organoleptissabunpadat Minyak Sereh Wangi (Cymbopogon nardur L) dilakukan

secaravisualdenganMengamatiperubah andaribentuk, aroma,warna setelah didiamkanpada suhukamar dalam jangka waktu 2 minggu.Hasiluji organoleptis dapat dilihat padatabel II :Tabel II. Hasil Uji Organoleptis Sabun Padat Minyak Sereh Wangi (Cymbopogon nardus L.)

\begin{tabular}{|c|c|c|c|c|}
\hline \multirow{2}{*}{ Formula } & \multirow{2}{*}{ Organoleptis } & \multicolumn{3}{|c|}{ Hari ke- } \\
\cline { 3 - 5 } & & $\mathbf{1}$ & $\mathbf{7}$ & $\mathbf{1 4}$ \\
\hline \multirow{2}{*}{ F0 } & Bentuk & Lunak & Padat & Padat \\
& Warna & Pink & Pink & Pink \\
& Aroma & Tidak ada & Tidak ada & Tidak ada \\
\hline \multirow{2}{*}{ F1 } & Bentuk & Lunak & Padat & Padat \\
& Warna & Pink & Pink & Pink \\
\hline
\end{tabular}




\begin{tabular}{|c|c|c|c|c|}
\hline & Aroma & Sereh Wangi & Sereh wangi & Sereh Wangi \\
\hline F2 & Bentuk & Lunak & Padat & Padat \\
& Warna & Pink & Pink & Pink \\
& Aroma & Sereh Wangi & Sereh Wangi & Sereh Wangi \\
\hline F3 & Bentuk & Lunak & Padat & Padat \\
& Warna & Pink & Pink & Pink \\
& Aroma & Sereh Wangi & Sereh Wangi & Sereh Wangi \\
\hline
\end{tabular}

Dari hasil uji organoleptik diketahui bahwa masing-masing keempat formulasi mengalami perubahan bentuk yang mulanya hari ke-1 lunak, karena reaksi saponifikasi belum terjadi secara keseluruhan, sehingga basa alkali belum bereaksi dengan asam lemak secara sempurna (Sukawaty, dkk. 2016) pada hari ke-7 sabun telah padat, kemudian pada hari ke-14 sabun tetap padat. Perbedaan aroma dari keempat formulayaituformula F0 aroma tidak ada , formulaF1,F2 dan F3 memiliki aroma sereh wangi. Semakin tinggi konsentrasiminyak atsiri Sereh Wangi semakin spesifik aroma sabun.Perubahan aroma ini disebabkan karena adanya perbedaan konsentrasiminyak atsiri Sereh Wangikarena semakin besar penambahan minyak atsiri Sereh Wangi (Cymbopogon nardur L)pH sabun semakin besar, Sabun yang memiliki $\mathrm{pH}$ tinggi atau rendah dapat menyebabkan iritasi pada kulit, sabun yang terlalu basa dapat menyebabkan kulit menjadi kering

b. Hasil Uji PHPemeriksaan pH sabunpadat minyak Sereh Wangi (Cymbopogon nardus L)dilakukan2 minggu waktu penyimpanan.Data dapat dilihat pada tabel III,

Tabel III. Hasil Uji pH Sabun Padat Minyak SerehWangi(Cymbopogon nardus L.)

\begin{tabular}{|c|c|c|}
\hline \multirow{2}{*}{ Formula } & \multicolumn{2}{|c|}{ Hari Ke- } \\
\cline { 2 - 3 } & $\mathbf{7}$ & $\mathbf{1 4}$ \\
\hline F0 & 8,5 & 8,7 \\
\hline F1 & 8,3 & 9,4 \\
\hline F2 & 8,8 & 9,6 \\
\hline F3 & 10,1 & 10,4 \\
\hline
\end{tabular}

Hasil nilai $\mathrm{pH}$ sabun padat minyak atsiri Sereh Wangi (Cymbopogon nardur L) dari hari ke-7 dan hari ke-14 $\mathrm{pH}$ tersebut rata-rata $8,7-10,4$. Keempat formula masih dikategorikan aman digunakan dan bisa diterima karena menurut SNI standar pH sabun yaitu 9-11.

$$
\text { Menurut Febriyenti }
$$

sabun dengan $\mathrm{pH}$ yang cukup basa bila digunakan akan meningkatkan $\mathrm{pH}$ 
kulit, tetapi kulit memiliki kemampuan untuk mengembalikan $\mathrm{pH}$ kulit seperti semula segera setelah dibilas dalam jangka waktu 15-30 menit.Pada F3memiliki konsentrasi yang lebih tinggi dibandingkan dengan formulaF0,F2,F3,sedangkan $\mathrm{pH}$ yang terlalu asam dapat mengiritasi kulit.

\section{c. Hasil Uji Tinggi busa}

Sabun padat minyak Sereh Wangi (Cymbopogon nardus L.) diuji selama 2 minggu dari perbandingan keempat formula di dapatkan hasil tinggi busa yang berbeda, dapat dilihat pada tabel IV

dan gambar 6. Dibawah ini :

Tabel IV. Data Hasil

UjiTinggiBusaSabun PadatMinyak Sereh Wangi

\begin{tabular}{|c|c|c|}
\hline \multirow{2}{*}{ Formula } & \multicolumn{2}{|c|}{ Stabilitas Sabun } \\
\cline { 2 - 3 } & ari ke 7 & ari ke 14 \\
\hline F0 & $9 \mathrm{~cm}$ & $6 \mathrm{~cm}$ \\
\hline F1 & $7 \mathrm{~cm}$ & $5,5 \mathrm{~cm}$ \\
\hline F2 & $8,5 \mathrm{~cm}$ & $5 \mathrm{~cm}$ \\
\hline F3 & $7 \mathrm{~cm}$ & $7 \mathrm{~cm}$ \\
\hline
\end{tabular}

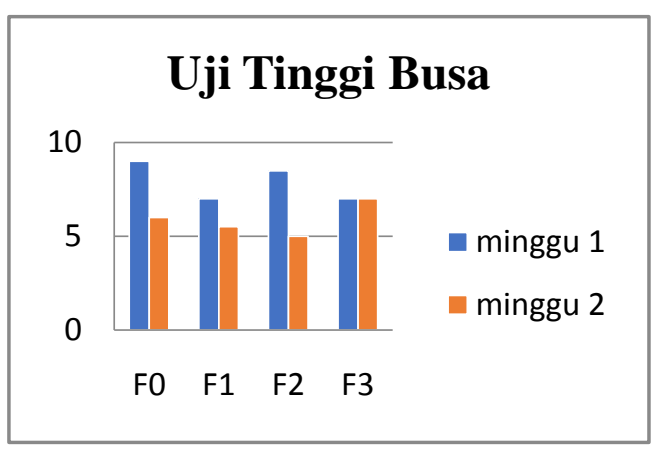

Gambar 6. Grafik Hasil Uji Tinggi Busa Sabun Padat Minyak Sereh Wangi Cymbopogon nardus L.)

Hasil dari pengujian tinggi busa sabun padat minyak Sereh Wangi ( Cymbopogon nardur L )dari hari ke7dan hari ke-14 terdapat perbedaan nilai tinggi busa pada saat penambahan minyak Sereh Wangi (Cymbopogon nardur L)yang digunakan dalam formula sabun tersebut, semakin tinggi konsentrasi minyak Sereh Wangi (Cymbopogon nardur L) semakin rendah tinggi busa. Tidak ada persyaratan tinggi busa minimum atau maksimum untuk sediaan sabun, karena tinggi busa tidak menunjukkan kemampuan dalam membersihkan (Rahayu,2009).

\section{d. Hasil Uji Stabilitas busa}

Uji stabilitas Sabun padatminyakatsiri Sereh Wangi (Cymbopogon nardus L.) selama 2 minggu didapatkan hasil yang dapat dilihat pada tabel $\mathrm{V}$ :

Tabel V.Data Hasil Uji Stabilitas Busa Sabun PadatMinyak Sereh Wangi(Cymbopogon nardus L.)

\begin{tabular}{|l|r|r|}
\hline \multirow{2}{*}{ Formula } & \multicolumn{2}{|c|}{ Stabilitas Sabun } \\
\cline { 2 - 3 } & ari ke 7 & ari ke 14 \\
\hline FO & $89 \%$ & $92 \%$ \\
\hline F1 & $93 \%$ & $100 \%$ \\
\hline F2 & $89 \%$ & $100 \%$ \\
\hline F3 & $86 \%$ & $93 \%$ \\
\hline
\end{tabular}




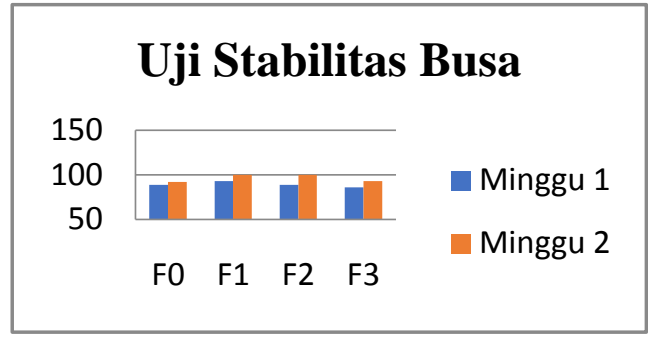

Gambar 7. Grafik Hasil Uji Stabilitas busa Sabun Padat Minyak Atsiri Sereh Wangi (Cymbopogon nardus L.)

Pada Tabel V Hasil Uji Stabilitas Busa dari setiap Formula Fo,F1,F2 dan F3 selama 2 minggu menunjukkan nilai yang hampir sama. Rata - rata nilai stabilitas busa untuk semua perlakuan berkisar antara 89$100 \%$. Stabilitas busa bertujuan untuk mengetahui kestabilan busa yang dihasilkan oleh sabun padat minyak atsiri sereh wangi, dengan penambahan cocomid DEA dan minyak kelapa sebagai surfaktan dan penstabil busa pada sabun. kriteria stabilitas busa yang baik yaitu apabila dalam waktu 5 menit diperoleh kisaran stabilitas busa $60-70 \%$. Pada penggunaanya busa berperan dalam proses pembersihan dan melimpahkan wangi sabun pada kulit (Hernani 2010).

Pada umumnya konsumen beranggapan bahwa sabun yang baik adalah sabun yang menghasilkan banyak busa, padahal banyaknya busa tidak selalu sebanding dengan kemampuan daya bersih sabun.Karakteristik busa sendiri dipengaruhi oleh adanya bahan aktif sabun atau surfaktan atau penstabil busa.Busa yang banyak dan stabil lebih disukai daripada busa yang sedikit atau tidak stabil.Busa dapat stabil dengan adanya zat pembusa.Zat pembusa bekerja untuk menjaga agar busa tetap terbungkus dalam lapisan lapisan tipis, dimana molekul gas terdispersi dalam cairan. Larutan yang mengandung bahan aktif akan menghasilkan busa yang stabil bila dicampur dengan air.

\section{KESIMPULAN}

Minyak atsiri Sereh Wangi (Cymbopogon nardur L) dapat dibuat menjadi sabun padat.Variasi konsentrasi minyak atsiri Sereh Wangi (Cymbopogon nardur L) formula F0, F1,F2 dan F3 dapat mempengaruhi sifat Fisik sabun

\section{DAFTAR PUSTAKA}

Eko, Y. F., Patar J. S., Mahfud., Pantjawarni.P.,2012.Pengam bilan Minyak Atsiri dari Daun dan Batang Serai Wangi (Cymbopogon winterianus) Menggunakan Metode Distilasi Uap dan Air dengan Pemanasan Microwave. Jurusan Teknik 
Kimia, Fakultas Teknologi Industri,ITS.

Fatimah dan Jamilah, 2018,

Pembuatan Sabun Padat
Madudengan Penambahan
Ekstrak Kunyit (Curcuma
domestica),Jurnal Teknologi
Agro-Industri Vol. 5 No. 2
(2018) Kalimantan Selatan

Febriyenti, Sari L.I, NoF1ta R. 2014.Formulasi Sabun Transparan Mintak Ylang-Ylang dan Uji Efektivitasterhadap Bakteri Penyebab Jerawat.Jurnal Sains Farmasi \& Klinis (ISSN: 2407-7062) | Vol. 01 No. 01

Hanaa, A. R. M. Sallam, Y.I. ElLeithy, Y.I. Aly, S.E. 2012. Lemongrass (Cymbopogon citratus) essential oilasaffectedbydryingmethods. A nnalsofAgri- cultural Science. 57 (2):113-116.

Hernani, H., Bunasor, T.K., F1triati, F., 2010.Formula sabun transparan antijamur dengan bahan aktif ekstrak lengkuas (Alpinia galanga L.Swartz.), Bul. Penelit.Tanam.Rempah dan Obat 21.

Konsentrasiohman, Asep. 2010.Eksplorasi Minyak Atsiri
Se- bagai Bioaditif Bahan Bakar Solar. Universitas Pendidikan Indonesia.Bandung.

Ketaren,S.1985.PengantarTeknologi MinyakAtsiri.PN Balai Pustaka.Jakarta.

Liza, Yulia Mona, et al. "Sol Gel: Principle And Technique (A Review)." (2018).

Rahayu, Iman., (2009), Praktis Belajar Kimia 1, Penerbit Departemen Pendidikan Nasional, Jakarta

Sukawaty Y., Warnida .,Artha Ananda. 2016. Formulasi Sediaan Sabun Mandi Padat ekstrak Etanol Umbi Bawang Tiwai (Eleutherine bulbosa (Mill.)Urb.). Media Farmasi Vol. 13 No. 1 Maret: 14-22

Yulia, E., Suganda, T., Widiantini, F., \& Prasetyo, R. I. (2015).Uji keefektifan antijamur ekstrak air rimpang lengkuas (Alpinia galanga [L] willd.) sebagai perlakuan pratanam untuk mengendalikan

Colletotrichum spp. pada kedelai (Glycine max L.).Agrikultura, 26(2). 

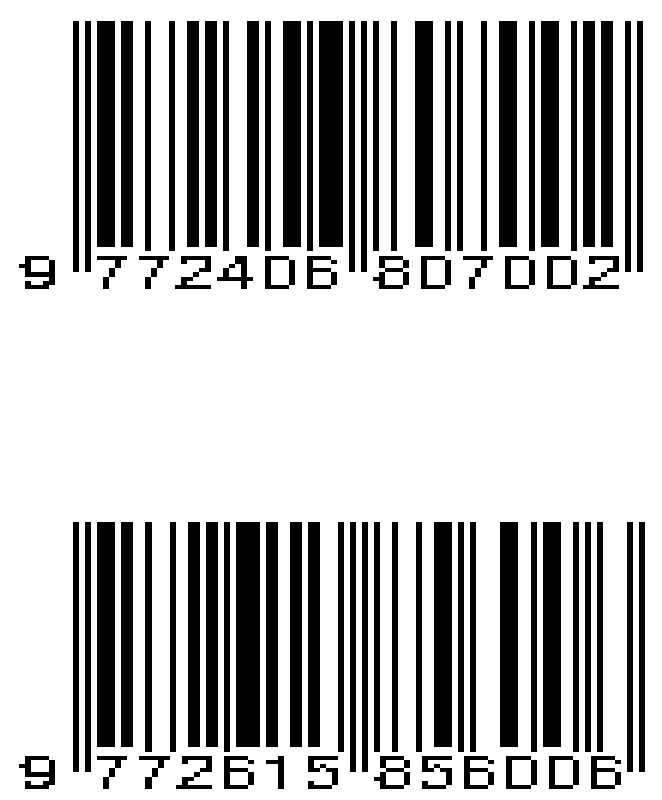